\title{
Role of HRM in Talent Retention With Evidence
}

\author{
Doreen Akunda ${ }^{1}$, Zhixia Chen ${ }^{1} \&$ Simon Ndwiga Gikiri ${ }^{2}$ \\ ${ }^{1}$ College of Public Administration, Huazhong University of Science and Technology, Wuhan, China \\ ${ }^{2}$ College of Sociology, China Central Normal University, Wuhan, China \\ Correspondence: Doreen Akunda, College of Public Administration, Huazhong University of Science and \\ Technology, Wuhan 430074, P. R. China. Tel: 86-131-2508-4429.
}

Received: March 16, 2018

doi:10.5430/jms.v9n2p8
Accepted: April 9, 2018

Online Published: April 19, 2018

URL: https://doi.org/10.5430/jms.v9n2p8

\begin{abstract}
Talent management and retention are increasingly seen as an essential practice in business sustainability strategies. It has since expanded from the sporting fraternity and the arts, particularly in the entertainment industry to become a global practice. This paper discusses the purpose and strategies used for talent management. Using a case study approach that combines the use of Reflexive Account (a retrospective analysis) and content analysis of firm reports, this paper identifies the Human Resource management practices implemented by one firm, MTN-Uganda as a case that provides human resource practitioners with evidence of the practical utility of various talent management and retention strategies. The primary sources of information used in reporting on the case were obtained through reflexive analysis (2012-2015) and content analysis of firm reports (2007-2018). Information gaps were filled in by contact and answered queries through the Department of Corporate Services at MTN Uganda.

Although there are many strategies for implementing talent management programs, their success is primarily pegged on the use of a mixed approach, with the Human Resource functions being supported by other management divisions to realise the return on investment sought through the implementation of talent management programs.
\end{abstract}

Keywords: talent management, employee retention, attrition rates, MTN Uganda, human resource

\section{Introduction}

Going by recent surveys on the impact of human resources on the future of business, Human Resource Managers ought to be concerned as more employees tend to be actively seeking for alternative employment and are ready to quit their current job positions (Boswell, Gardner, \& Wang, 2016). A survey by TNS for the Conference Board reports that employee satisfaction levels in the United States had dropped from 61.1\% in 1987 to about $45 \%$ last year (Heathfield, 2016).

Reitman (2007) noticed a trend in the past decade in which, compared to the past, employees' concerns have shifted to seeking for job satisfaction and a sense of worthiness and therefore are more willing to seek for an employer and careers that can provide them with these needs and not just a paycheck. Furthermore, employees want considerate managers, opportunities for growth and development in their chosen career, recognition for their hard work, rewards for their achievements and careers that enable employees to balance work and family life notes Reitman (2007).

These recent developments seem to support the position taken by the Aberdeen Group (in 2005) that human capital management will remain to be an essential component that will determine future growth of businesses, starting with the easily discernable concern of cost saving due to employee attrition and turnover.

This paper is a contribution that informs on the roles and responsibilities that Human Resource Managers ought to be able to meet regarding talent management and retention. It goes on to discuss examples of talent and employee retention strategies that Human Resource Managers can make use of to achieve this aim cost-effectively for the sustainability of their businesses based on the reflections of how one firm-MTN Uganda has integrated some of the strategies identified through the literature review in its operations within the Ugandan Telecommunications Market.

\section{The Rationale for Talent Management and Retention}

The focus on talent retention has been growing going by the recent history, but its prominence is thought to be associated with the early years of market liberalisation and has continued to be amplified by the ongoing processes of globalisation (Silzer \& Dowel, 2009, p. 54). 
Expansion of global trade, expansion of companies through mergers and acquisitions, for example, has seen small and big companies tapping into new markets (in new countries) (Phillips \& Edwards, 2008, p. 253). These have, in turn, created a need to recruit new talent and retaining knowledgeable employees capable of driving and sustaining growth in the new market frontiers. In such situations, it is necessary for human resource managers to design and implement new talent and employee retention programs as a way of building a strong foundation to promote an organisational culture intended to groom the new business start-ups for success (Tsui \& Lai, 2009, p.253).

Kontoghiorghes (2016) has explored the relationships between different organisational cultures and talent attraction, development and retention. Kontoghiorghes identified and classified corporate cultures as; (i) Adaptability-external environment, (ii) Clan-employee involvement (participation), (iii) Mission-defines organizational vision, purpose and goals and, lastly (iv) Bureaucratic-internal focus. This work has ascertained that high-performance organisational cultures predicted talent attraction and retention. The study by Kontoghiorghes found that talent attraction and retention to be highly associated with the extent to which an organisation is perceived to have a change-quality, technology-driven culture and which is characterised by support for creativity, open communications, effective knowledge management, and the core values of respect and integrity. This study concluded that strategically aligned and ethical high-performance organisational cultures have strong effects on talent attraction and retention and are also highly conducive to the development of high commitment and motivating work systems (Kontoghiorghes 2016).

Therefore, it is discernable that there are linkages between talent management and organisational culture which can be discussed as bidirectional-having direct and indirect effects on the outcomes of particular talent management strategies. The attributes of high-performance organisational cultures noted by Kontoghiorghes can be considered either as collective or individual predictors of talent retention. Another study by Sheridan (1992), found culture to have a stronger effect on employee retention than the combined influences of the labour market and employee characteristics. In addition to retention, however, organisational culture greatly influences and shapes HR strategy formulation, including such strategies as employee selection and placement, employee promotion and development, and reward systems noted Sheridan (1992).

Sheridan (1992) further explains that organisational culture consistently fosters specific management practices that directly influence ethical behaviours that lead to different performance. Different strategies result in psychological climates that also affect levels of commitment to retention among employees working in different organisations. Another study by Alnaqbi (2011) established that organisational culture exerts influence on a wide range of variables including job satisfaction, organisational commitment and performance. For multinational companies, talent retention models that may have been successful in one country may need modification owing to cultural dynamics which are known to differ from one country to another.

Also, no human resource manager is likely to be happy when he/she loses talented employees to a rival firm (Tsui \& Lai, 2009, p. 253). These reasons provide the underlying rationale that forms the basis for retaining talented employees as well as attracting new talent to a company. To be able to accomplish this task, human resource managers need to come up with creative or innovative talent recruitment and retention programs. Such programs aim to attract and motivate talented employees to be focused on their jobs as well as in a manner that instils loyalty to their employers. Zhang and Stewart (2017) however emphasised that talent management should not be only about attracting and retaining, but also reviewing the organisational needs and letting go of the unrequired talent.

Regarding talent retention, many businesses today face enormous challenges (as highlighted above) which may consequently make it challenging to attract and retain talent, sometimes in the long term, they end up losing their most talented employees. The factors mentioned earlier on, and employee poaching which is nowadays all too common could partially be used to explain why HRM has an immensely important role to play in organisational growth. Because comobility leads to transfer of information, social relationships become significant because employees held up in particular organisations jointly move to 'better' firms (Marx \& Timmermans, 2017).

With employee performance on the decline as well as the increasingly common observation that employees intend to leave their current job place as they do not see better prospects with their current employer, talent retention becomes a significant consideration. Additionally, specific working conditions such as heavy workloads and too much pressure from line managers that leave employees overly exhausted have been cited by employees as being reasons for talented employees to leave their current employers.

Apart from the workplace dynamics, many businesses today find themselves operating in highly competitive environments. Competition applies to both start-up businesses and established businesses which, based on their market share in industry and years of dominance can be regarded as mature businesses according to the business valuation model. Based on valuation, mature businesses are those with established market history and have 
well-established investment and financing structures (Scullion \& Collings, 2010, p. 175). So, it is imperative for human resource managers in any business to be able to maintain a reliable structure for the recruitment and retention of the needed talent pool as a way of ensuring the growth of their business both in the short term and long term (Phillips \& Edwards, 2008, p. 28).

As people continue to work for individual firms, there are tendencies for various stakeholders to identify with specific individuals strongly. Such individuals are influential brand ambassadors, and their departure can result in shifts in customer base. There are instances where the departure of a manager in a successful firm corresponds directly with a change on a company's share performance on the stock market. In other innumerable instances, some valuable customers will only feel comfortable being attended to by individual employees. Often, such attachments are because of long-term contact between the employees and the customers. By identifying and retaining such employees, business firms can be able to maintain and expand their customer base (Phillips \& Edwards, 2008, p. 324).

Owing to the impact it can have on the productivity of a workforce, talent and employee retention should be regarded as a continuous process rather than a static duty to be occasionally performed when a need to recruit or replace an employee arises (Taylor, 2002, p. 229). When talent and employee retention programs are managed efficiently, the elusive goal for many business organisations; that of retaining talent can be achieved. There are numerous cases where a company identifies a talent, nurtures it through training and eventually loses it to a competing firm.

On an extreme level perhaps, there are instances where experienced employees or talented ones set out on their own to establish competing firms. These are sobering realities that necessitate carefully designed talent and employee retention programs to minimise losses of productivity, time and resources used in nurturing employees occasioned by employee turnover and natural attrition.

So, talent retention programs can act as cushions against loss of organisational knowledge which is an essential tool for driving growth and sustainability as emphasised by Wadhwa, Bodas Freitas, and Sarkar, (2017). As a process, talent retention requires the identification, implementation, and evaluation of the effectiveness of different strategies aimed at fostering employee loyalty to their employing organisations and the human resource managers are often given the lead role in doing these tasks (Taylor, 2002, p. 229).

Notably, Bermiss and Mcdonald, (2018) hypothesised in their research that employees with conservative ideology tend to depart and settle for organisations that fit their ideologies compared to liberalists. This realisation requires HR managers to introduce employees to the organisational culture during the induction process. Organisational socialisation plays an essential role in newcomer adjustment and transmission of the organisational culture (Klein \& Weaver, 2000). Socialisation is a continual process that extends throughout an individual's tenure with an organisation and across organisation throughout one's career (Klein, Polin, \& Sutton, 2015).

Tan \& Shen (2016), provide that the social domain is important as it serves as an essential indicator of an employee's knowledge of how to function successfully with coworkers and supervisors. Competence, commitment and satisfaction are therefore some of the apparent factors for evaluating the efficiency of newcomers.

Often, organisations provide newcomers with assistance in mastering tasks immediately after entry and helping them to focus on building social relationships after being hired. The probation period at MTN Uganda varies across departments. However, its standard for new hires to serve under probation for three months. This probatory period marks one of the defining socialisation experiences of newcomers in MTN. The first seven months spent by a newcomer in an organisation provide managers with opportunities to find practical approaches to maintain job attractiveness and to compensate for the reality shock that sets in within this period.

Klein \& Polin (2012) in Batistic, (2018) talk about individual activities and plans that help to facilitate their socialisation. Some of these activities are referred to as transition activities. Tang, Liu, Oh, \& Weitz (2014) emphasise the practical implications of HRM systems on how newcomers can easily benefit from socialisation plans. Socialisation agents (supervisors, leaders, workers, administrative assistants, mentors, HR representatives etc.) offer information, provide resources and otherwise, assist newcomers during their acculturation. It is common that proactive behaviours are emphasised during the socialisation process (Klein et al., 2015).

Thus, it is of utmost importance for executives involved in one or more ways of executing various responsibilities in talent or employee retention program to be more creative or innovative than those working for their competition. Such executives may, for example, involve apart from the human resource managers, the midlevel managers in charge of various operations for they can provide great insights on the issues associated with employee performance stagnation in their respective workplace jurisdictions. 


\section{General Roles of HRM in Talent Management and Retention}

HRM primarily plays three significant roles regarding talent management and employee retention. First is to identify the overall cost of employee turnover, followed by assessing reasons behind employee turnover and then designing, implementing and evaluating employee loyalty programs. These broader roles are subdivided into various tasks that HR managers need to accomplish. In the latter section, MTN Uganda shall be used as a case to explain and illustrate in detail the strategies used to accomplish these roles.

To begin with the second role, HR managers should strive to understand the reasons why employees leave. This involves assessing if the turnover is attributable to obvious reasons such as job mismatch that relates to job dissatisfaction or job difficulties linked with personality differences. Other aspects like limited opportunities for career growth versus the availability of better jobs that offer the desired opportunities for personal growth and non-appreciation of employees by the management can be strong push factors. However, Tan and Rider, (2017) embrace departure of employees to rival companies as prestigious saying it is an advancement for competitors and it serves the benefit of career growth. Additionally, the inability of the supervisors and the management to resolve employer-employee conflicts is another factor in this case (Pinnington, Macklin, \& Campbell, 2007, p. 141).

Furthermore, HR managers need to understand that some employees may leave because they feel that their compensation package is inadequate especially when compared with what other employers are offering for the same job. To some, stressful working conditions can be a demotivator and a compelling reason for them to move. Finally, if employees work in situations that are characterised by lack of support, either from the management or colleagues, there is a higher probability that some employees may leave (Bennekom \& Keith Goffin, 2002, p. 28). As easy as it may seem to be, HR managers ought to be discerning enough to be able to accurately identify some of the not so obvious reasons causing employee turnover.

They can put in place a communication system that provides real-time feedback between the managers and the employees. Employee exit interviews as earlier noted can also provide valuable feedback (Cascio \& Boudreau, 2010, p. 83). Considering the first role, that of identifying and estimating cost due to employee turnover HRM roles involve calculating employee turnover estimates on a periodic basis as well as those differentiated by types of employee. Intimately connected with this role, HRM should conduct analyses between the rates of turn over experienced within the organisation with those of other organisations in the same industry. This analysis can be used to determine if the turnover rates are healthy or not ( Phillips, 2000, p. 63).

The estimation of employee turnover rates within an organisation helps the organisation to know the cost the organisation incurs as a result of employee turnover. Regarding the third HR role of designing, implementing and evaluating employee loyalty programs, HR managers are obligated to identify strategies that can be used to retain their employees within the organisation. Though such strategies will differ from organisation to organisation, they all serve the primary function of motivating employees to continue working for the organisation. Their specific duties in part involve; identifying incentives which can boost the productivity of employees notes Stadius (1999, p. 178). These incentives can be monetary and non-monetary rewards given to employees or also include realigning duties which can instil a sense of responsibility in an employee so that employees can give quality work.

Human resource managers are similarly tasked with the duty of ensuring that their organisations can provide their employees with opportunities to grow their careers as well as other personal aspects such as family life (Yu, Yu, \& Zhao, 2011, p. 109). Other responsibilities are tied to creating an enabling work environment, providing a safe working environment for employees, providing avenues for self-improvement and opportunities through which employees can realise their full potential (Feldman \& Miller, 1998, p. 215). Grobler and De Bruyn (2011) in their study about Flexible Work Practices (FWP) add that organisations should aim at incorporating organisational desired changes as an ultimate result.

By continuously being able to address the emerging work-related concerns, human resource managers above all these roles must evaluate the strengths and weaknesses of the strategies they choose for employee retention. Through evaluation, it becomes easy to identify which strategies are working and which ones are not as explained by Grigoroudis and Yannis (2009, p. 75).

\section{Strategies for Talent Management and Retention}

Whereas it is possible to describe with clarity strategies used by HR managers in business organisations, there is little written to guide them, in a stepwise fashion about talent and retention programs (Stefan, Julian, Kathryn, Fredrik, \& Till von Wachter, 2008, p. 205). Most employee retention programs have been developed from case studies and trial and error. Three elements (components) are evident; the first element centres around recruitment of the best talent, 
the second component is centred around employee motivation while the last component, arguably the most challenging for many business organisations is talent retention.

All the three components, if conceptualised and implemented well can be productive in that firms can reduce employee turnover, improve performance through employee motivation and at the same time increase future recruitment rates looking at the elites that have often proven knowledgeable skills required in the business environment in the context of socio-cultural strategies as highlighted by Marquis and Raynard (2015). Muratbekova-Touron, Kabalina, and Festing, (2017) pointed out three major factors that depict talent management as recruitment and selection, training and development and lastly retention. All these are consequently associated with positive developments regarding the improved overall performance of the business.

The extent to which a retention program will yield positive results is equally subject to internal and external factors notes (Stefan et al., 2008, p. 205). Internal factors in this case are; a commitment by the management to avail the needed resources to do human resource audits, capacity building, and other related activities, while an external factor may be market forces which may positively or negatively affect business performance. The poor performance of an organisation in this regard translates to reduced capacity by the business to avail the needed resources that initiate, run or even sustain an employee retention program in line with the strategic business goals (Stefan et al., 2008, p. 205).

Additionally, these components let employees feel granted autonomy to make decisions for what they need. Some employees may want resources in form working tools to perform responsibilities availed to them, and others need a modified workplace environment in a way that employees can derive satisfaction from their work-related activities.

Furthermore, if HR managers can create supportive structures for their employees, organisations can be in a position to protect their employees. A commonly cited example of a supportive service is providing day-care for nursing mothers in the workplace. Such workplace cultures make employees loyal as they cherish the core values of their organisation (Kossek \& Lambert, 2005, p. 163).

To some, rewards that add value to their life, job satisfaction or show appreciation for their efforts are their top priority (Cumming, 2004, p. 10). However much interests vary from generation to generation; good pay remains an essential strategy to most employers. Jackson, Schuler, and Werner (2011, p. 383) add that most employees feel loyal if they feel that their pay is according to their industry's standard after making a comparison with colleagues engaged in almost the same duties but different organisations.

Zhang and Stewart (2017) have highlighted that Employer Branding, Organisation attractiveness and managing of talent as other essential strategies that HR should pay constant emphasis. According to the Hay Group (2014), the catch for human resource managers is that in case they ignore the felt needs of their employees and fail to address them, their competitors will which brings about turnover.

Putting in place a reward and recognition program can also serve to keep employees to the company through positive recognition for work done by employees. Awards such as the best employee of the month or other awards based on commonly agreed on criteria within the company to recognise outstanding qualities in employees working for a particular business organisation is a good strategy for employee retention (Nelson \& Spitzer, 2003, p. 14).

This recognition, when linked to performance-based bonuses, employees can relate their work performance with that of their employer (Marquardt, 2011, p. 48). Performance-based bonuses work better when they are based on the productivity of the employees. A slight variation of the performance-based bonuses is the use of retention bonuses (WorldatWork, 2007, p. 361; Malena, 1995). These are particularly useful in particular industries which experience above than average levels of attrition. An important aspect of recognition, which is project-based performance varies greatly and can involve the use of monetary or non-monetary gifts such as paid holidays and travel opportunities as noted by Cui, Khan, and Tarba (2016).

Furthermore, organisations can choose to award prized gifts to their employees when marking significant milestone achievements; the employees helped the organisation to achieve. Some companies are for example known to appoint such employees to the boards of directors or even transferring some share to the employee.

Gifts can also be given to employees during anniversaries, jubilee celebration or similar events such as internationally recognised certifications, for example, the ISO certification. Involving employees in such events communicates that the organisation is mindful of them (Gartner \& Lime, 2000, p. 33).

A good communication system within an organisation also serves as an essential tool in enabling the business organisation to manage and retain its talent. It tends to foster employee loyalty compared to situations where 
activities happening within an organisation are shrouded in mystery. It creates a state of considerable confusion and employees can make easy exits when they conclude that things within their organisation are not likely to improve yet it is all in hearsay (Hernandez, 2009, p. 257). Effective communication is also closely tied to constructive feedback mostly about employee performance ( McPhie, 2009, p. 4).

These strategies are used to maintain active engagements with employees, helping them to remain loyal to the company. Optimization of employee engagement is widely thought to produce improvements in employee productivity as well as winning the hearts of employees and consequently, their commitment to the organisation (Albrecht, 2010, p. 359). Open communication can be helpful in retaining employees especially during periods of uncertainties which are beyond the control of the management such as negative political undertones affecting business performance or even global factors such as the recent global economic crisis.

Also, communicating about changes that occur within the organisation and their long-term duty in line with the changes also help in talent retention because in a way it creates a sense of ownership to the organisation. However, the approach on how such communication is made has to be carefully thought out (Goodman \& Hirsch, 2010, p. 81).

Another employee strategy that makes a difference in employee retention is the use of coaching and mentoring, which mostly works well for employees that record positive performance in their respective responsibilities. Employees whose work performance is affected by problems of communication, primarily interpersonal, can be assisted through to overcome them. Strategically planned sessions can in the long-term help organisations to have loyal employees. It is through these sessions that employees are introduced to career development programs that offer training and award certificates upon completion of courses offered in the company/ organisation.

The other means through which the management can retain talent is by assisting their employees. Such assistance, for example, may include support when employees are faced with personal issues and emergencies with their close family members and enabling employees to achieve personal development goals (Kossek \& Lambert, 2005, p. 163).

By managing employee turnover levels to a healthy minimum, an organisation will, with time be associated with a positive image in the market hence becoming a preferred employer for many (McConnell, 2011, p. 215). Achieving this will involve the organisation going an extra mile than just providing a structured base pay for their employees. Such initiatives can boost the morale of the employees who already constitute the current workforce of the business organisation. Strategies enacted to manage employee turnover should be able to reflect the long-term objectives the business intends to achieve (Brown, 2005, p. 219).

Managers involved in operational management can also choose to delegate their decision-making authority to their junior staff that shows promising qualities of being responsible for their current and even additional job responsibilities. Through delegation, managers can communicate the trust they have on the employees' ability to execute a specific duty (Vallabhaneni, 2009). Giving extra responsibilities makes employees loyal, and at any time, managers are in a position to defend them in case of grievances.

The creation and use of internships is an example that training institutions and employers have been using as an opportunity to develop skills and to identify promising recruits (Arthur, 2001, p. 313). As a practice, it is a proactive approach useful in building partnerships between employers and training institutions that can produce right candidates with the knowledge and specific skills needed by the employers.

Following successful recruitment, HR managers then use employee training/capacity building to enhance employee skills, team building events, mentoring, attractive work packages, modifications of the work environments, promotions and reward schemes to motivate and retain employees.

In implementing all the strategies mentioned above, business organisations hope to retain and protect their workforce. Wadhwa, Freitas, and Sarkar, (2017) in their study on Research and Development (R\&D) emphasised on knowledge leakage as a factor that firms should consider to avoid employee turnover given their business competitors. Having a quality workforce means that operations can run as planned and this improves productivity.

\section{Methodology: The Case Study Approach}

This case study integrates the use of a reflexive account of a former employee at MTN Uganda and the Content Analysis of secondary data obtained from firm reports of the MTN Group spanning the period 2007-2018. The reflexive account is provided by an employee who did not serve in a high-level managerial position for three years between 2012-2015. The reflexive analysis, as used for a Case Study is a methodological approach that has been applied by Taylor \& Land (2014) and Langley \& Royer (2006) in the study of organisational management and organisation practices. 


\section{HRM Practices at MTN Uganda}

The previous section identified and explained the significant roles of HRM in talent management, as well as the various strategies that can be used in the acquisition, management and retention of talent. This section concentrates on the HR practices of MTN Uganda as a case with the aim of providing practical evidence on the utility of some of the strategies identified in the literature reviewed in the previous sections.

Founded in 1998, MTN Uganda is a telecommunications company under the MTN Group which has operations in about 22 countries, both in Africa and Asia (Bloomberg, 2018). It is the leading company in the telecommunications market in Uganda which has about seven competing Telcos. MTN maintains dominance in the market based on the market share and customer subscription base (MTN Group Limited, 2012, p. 60).

MTN Group employs a workforce of over 30,000 people (MTN.com., 2016). The provision of various services and products by MTN Uganda is dependent on a workforce distributed in the following vital divisions (departments); Corporate Service, Finance, Mobile Finances, Business Risk Management, MTN Business Enterprise, IT, Sales and Distribution and Customer Experience which holds most of the staff. Additionally, MTN Uganda ranks favourably as one of the top-ranked 20 companies to work for in Uganda (MTN Press Office, 2014).

Towards having a workforce that is motivated by and happy with the work MTN does and based on the recognition by MTN to attract talent in various divisions, mixed strategies have been used to attract and retain talented employees. Overall, the MTN Group has an HR policy that is focused towards promoting the diversity, development, motivation and best use of talent as outlined within the MTN's Employee Value Proposition (EVP) (MTN Group Limited, 2012). By the end of 2003, Wöcke, Bendixen, and Rijamampianina, (2007) reported that about 80 percent of HR policies in the MTN group were standardised across all the MTN operations. Examples of HR related policies that were standardised then included recruitment, job grading systems, remuneration policies and Human Resource Information Systems.

The first strategy used by the MTN group for talent acquiring and retention talent is by Training and Talent Development. Business Process Outsourcing is used to identify talents for different divisions. Talented employees who show exceptional promise of leadership are identified internally and groomed for higher responsibilities. For the MTN group to maintain a diverse and sustainable pool of talent which will meet the strategic goals of the firm, the group has over the years committed resources towards the training and capacity building of its staff. An integrated approach, that is strategically aligned is used in MTN during the process of talent identification as suggested by Wiblen, (2016). It is reported that the group committed about R383 million for development of talent and skills for its staff. The commitment towards staff training and development was estimated in 2012 to be $3.2 \%$ above the industry standard. The MTN group further reported (in 2014) spending about $6 \%$ of its payroll on training its staff (MTN Group Limited, 2014).

The MTN academy assumes a central position in developing internal efficiencies among the MTN staff (Douglas, 2012). The goals pursued by the MTN academy are complimented by the e-live online learning platform that is available 24 hours a day. Regional MTN learning centres located in Dubai, Accra and Johannesburg provide leadership training for identified talent. The MTN group also established an executive leadership flagship program (The Global Advancement Programme-GAP) in 2012 for employees with high leadership potential for critical business divisions undertaken in India and China. Similarly, the group is also implementing another leadership program for middle-level management cadres.

The second strategy used by MTN to retain talent has its anchoring on employee remuneration practices. Remuneration and human resources (R\&HR) committees, reporting to the management board identify and guide the implementation of decisions about employee remuneration. Hubbard and Palia in Fernandes, Ferreira, and Winters, (2017) said that a good salary pay could easily attract talented employees giving an example CEOs that are required in a competitive environment. A key strategy is ensuring remuneration is commensurate with performance, both at the individual and group level (MTN Group Limited, 2012, p. 77).

Thirdly, the MTN group has commitments to follow global labour practices, starting with an open recruitment policy which bars any discriminative practices. Being a multinational company, MTN tends to retain talent from a pool of expatriates from other countries within its operations (Grotto, Hyland, Caputo, \& Semedo, 2017). At the operational level, MTN gives priority to those whose jobs may have become redundant when new positions become available. Internal disciplinary policies also serve the vital role of protecting employees from arbitrary dismissals and ensure conformity with fundamental provisions of the International Labour Organisation and a guarantee of fundamental Human Rights (MTN Group Limited, 2012, p. 77). 
The Fourth strategy for talent retention at MTN are based on the nature of the work environment. Measures to ensure employee health and safety at the MTN group are diverse and include; employee representation in health and safety committees, provision of assistance and extended benefits against occupational exposure. Health and safety committees at the workplace monitor and offer advice on matters that affect the health and safety of employees. (MTN Group Limited, 2014).

Partnerships with assistance providers such as International SOS (ISOS) and the Control Risks Group (CRG) helps MTN to provide staff with critical assistance during situations of emergency and when the need for medical, evacuation, security, travel assistance arises.

Depending on contextual factors, MTN employees working in extraordinary situations are provided with necessary tools to enable them to work remotely, are given flexible working hours and can get home relocation, counselling services, safe transportation and even food vouchers. Employees working in high-risk environments such as High Electromagnetic Fields are required to undertake an annual compliance training and be certified.

A full range of other local solutions to workplace-related issues at MTN operations includes the provision of full or subsidised lunches at the workplace, provision of crèches for women, access to recreation time and facilities like gyms and sporting facilities, and employee compensation when environmental emergencies affect their work.

The fifth strategy used by MTN in talent retention is based on its Talent Engagement processes. Regular performance reviews and regular discussions are held throughout the year. Formal work performance reviews (led by local leaders) are conducted in January and July of each year. Through this processes, MTN maintains a culture of active performance engagement that has seen the development and utilisation of corrective action throughout the year (MTN Group Limited, 2012, p. 76). MTN has a partnership with Investors in People Standard (IIP) and has adopted the IIP framework in mainstreaming its talent development strategy.

The sixth strategy used by MTN to retain talent is based on its rewards and recognition programs. MTN uses the Hay Group job evaluation processes. These have been adopted and provide the foundation upon which the MTN group aligns responsibilities, performance and its employees to integrate project-based processes. Such programs are Corporate Social Initiatives that have an explicit social impact on both society and employees that are engaged in these projects (Bode, Singh, \& Rogan, 2015). Rewards and prizes are provided to MTN employees to instil a culture that is committed towards the MTN business goals.

Y'ello Stars is the reward and recognition program at MTN that's is perhaps widely known (Ntabgoba, 2013). It serves the roles of incentivising and rewarding top-performing employees. Through this programme, employees and leaders get to nominate their peers for their exceptional service and contributions. The program was launched in 2005 and has been a calendar event for MTN Uganda. Other recognition categories at MTN Uganda include the Employee of the Year and the monthly Quality Icon(s), Knowledge share, Customer Share and MTN Values Awards.

\section{Conclusions}

Unlike before, when talent management was only established in Europe and the United States and especially in the sporting fraternity and the arts-based industries such as entertainment, it is now applicable globally. There are compelling reasons that necessitate creation and sustainability of talent management and retention programs. These include; increasing competition, expansion of global trade, the need to minimise losses attributable to high employee turnover, diversification of the workforce regarding job expectations and job satisfaction, maintaining an existing customer base and safeguarding the public image of successful companies.

As noted above, the Human Resources function is an integral part of many business sustainability strategies including that of MTN Group's operations. HRM provides the insight and guides the processes critical for improving employee performance management, talent management, human capital development and allocation of resources linked to these functions.

There is a need for HR managers to be concerned going by research indications of falling levels of employee satisfaction with their current jobs. Lee, Hom, Eberly, and Li, (2017) underscore the importance of organisational commitment, job satisfaction, job embeddedness, shocks, willingness to stay or not as events that HR Managers should always appraise to retain talent.

As demonstrated by the case of MTN-Uganda, there is no single success formula for talent retention. Most of these programs will involve the use of mixed approaches. The kind of approaches to be used in these programs may at times vary with the business industry or even the cultural dynamics in the working environment. Looking at Asia for 
instance, most companies/organisations demand high authority conformity (Johennesse \& Chou, 2017). It is the role of HRM to identify which kind of approaches to use. Talent retention is tied to the need for organisations to protect their workforce from poaching and the high-cost organisations incur. Marx and Timmermans, (2017) explained comobility in their study how employees not only move owing to information from their co-workers but also social relationships are a critical factor that lets them cross to other organisations.

For each of the chosen approaches to be successful, the HRM must be supported by other levels of management to enable it to realise the full benefits of talent and employee retention programs. In addition to this, the persons with the responsibility of overseeing the implementation of these programs ought to understand the value of effective communication within an organisation and must be conversant with the ways of providing constructive feedback to the members who constitute part of their working groups.

The fundamental essence is that for multinational companies, the mere duplication of such programs from one country to another may be counterproductive in the long run. Basing the programs on the complexities reflected on the ground operations is what will largely determine if the programs are likely to succeed or not.

Lastly, to be able to run efficient talent retention programs, human resource managers ought to ensure that organisations should be able to realise the return on investment on such programs. These returns on investment are expected to be realised through the maintenance of healthy attrition rates within the organisation as well as the increased productivity by the employees which in the long term creates value for all the stakeholders of an any given organisation.

\section{Study Limitations}

There are several limitations in this research that merit mention. First, is the methodology used in doing the case study. This case study combines the use of a reflexive account of a former employee at MTN Uganda and secondary data obtained from firm reports of the MTN Group. The reflexive account is provided by an employee who did not serve in a high-level managerial position for three years between 2012-2015. Retrospective recall and short tenure are limitations that Klein et al. (2015) identify as posing the question of bias (for example in the case of an employee giving a retrospective account). Whereas this query will keep on coming up, retrospective accounts are valid sources of information for use in case study research so long as they are objectively balanced.

The second limitation (the tenure duration) is one that is also acknowledged in this paper. Significant changes may have occurred at MTN Uganda since 2015. Due diligence to fill information gaps, including efforts to make contacts and enquiries from the Department of Corporate Services at MTN Uganda on the current status of the issues discussed in this case study were made. Furthermore, firm reports were scrutinised and used for additional reporting.

\section{References}

Aberdeen G. (2005). Retaining Talent: Retention and Succession in the Corporate Workforce. Retrieved from http://www.rodinconsulting.com/docs/PubLink2_Aberdeen_RA-Retention_KJ.pdf

Albrecht, S. L. (2010). Handbook of employee engagement: Perspectives, issues, research and practice. Cheltenham: Edward Elgar Publishing. https://doi.org/10.4337/9781849806374

Alnaqbi, W. (2011). The relationship between human resource practices and employee retention in public organisations: an exploratory study conducted in the United Arab Edith Cowan University. Edith Cowan University. Retrieved from http://ro.ecu.edu.au/theses/424

Arthur, D. (2001). Employee recruitment and retention handbook. New York: AMACOM-American Management Association.

Batistic, S. (2018). Looking beyond - socialisation tactics: The role of human resource systems in the socialisation process. Human Resource Management Review, 28, 220-233. https://doi.org/10.1016/j.hrmr.2017.06.004

Bennekom, F. C. V., \& Goffin, K. (2002). Problem Prevention Through Design for Supportability: Gaining Competitive Advantage from Customer Support. Bolton: Customer Service Press.

Bermiss, Y. S., \& Mcdonald, R. (2018). Ideological Misfit? Political Affiliation and Employee Departure in the Private-Equity Industry. Academy of Management Journal, 61(1). https://doi.org/10.5465/amj.2016.0817

Bloomberg. (2018). Company overview of MTN Uganda Limited. Retrieved January 16, 2018, from https://www.bloomberg.com/research/stocks/private/snapshot.asp?privcapId=777331

Bode, C., Singh, J., \& Rogan, M. (2015). Corporate Social Initiatives and Employee Retention. Organization Science, 34, 1-19. https://doi.org/10.1287/orsc.2015.1006 
Boswell, W. R., Gardner, R. G., \& Wang, J. (2016). Is retention necessarily a win? Outcomes of searching and staying. Journal of Vocational Behavior, 98, 163-172. https://doi.org/10.1016/j.jvb.2016.11.006

Brown, D. R. (2005). The food service manager's guide to creative cost cutting: over 2,001 innovative and simple ways to save your food service operation thousands by reducing expenses, Volume 1. Florida: Atlantic Publishing Company.

Cascio, W. F., \& Boudreau, J. W. (2010). Investing in People: Financial Impact of Human Resource Initiatives (2nd ed.). New Jersey: FT Press.

Cui, W., Khan, Z., \& Tarba, S. Y. (2016). Strategic Talent Management in Services SMEs of China. Thunderbird International Business Review, 49(5), 630-631.

Douglas, K. (2012). How two of Africa's top companies keep their employees happy. Retrieved February 8, 2018, from https://www.howwemadeitinafrica.com/how-two-of-africas-top-companies-keep-their-employees-happy/20363/

Feldman, D. A., \& Miller Wang, J. (1998). The AIDS crisis: a documentary history. West port: Greenwood Publishing Group.

Fernandes, A. P., Ferreira, P., \& Winters, L. A. (2017). The Effect of Competition on Executive Compensation and Incentives: Evidence from a Quasi-natural Experiment. Journal of Human Resources, 53(1). https://doi.org/10.3368/jhr.53.3.0215-6963R1

Gartner, W. C., \& Lime, D. W. (2000). Trends in outdoor recreation, leisure, and tourism. Oxon: CAB International North America. https://doi.org/10.1079/9780851994031.0000

Goodman, M. B., \& Hirsch, P. B. (2010). Corporate Communication: Strategic Adaptation for Global Practice. New York: Peter Lang Publishing Inc. https://doi.org/10.3726/978-1-4539-1460-1

Grigoroudis, E., \& Yannis, S. (2009). Customer Satisfaction Evaluation: Methods for Measuring and Implementing Service Quality. New York: Springer.

Grobler, P. A., \& De Bruyn, A. (2011). Flexible work practices (FWP) - An effective instrument in the retention of talent. South African Journal of Business Management, 42(4), 63-78.

Grotto, A. R., Hyland, P. K., Caputo, A. W., \& Semedo, C. (2017). Employee Turnover and Strategies for Retention. In The Wiley Blackwell Handbook of the Psychology of Recruitment, Selection and Employee Retention (pp. 445-472). Wiley-Blackwell. https://doi.org/10.1002/9781118972472.ch21

Hay, Group. (2014). UK talent exodus on the horizon as economic outlook improves. Retrieved from atrium.haygroup.com/uk/your-challenges/misc.aspx?id=3878

Heathfield, S. M. (2016). Keys to Employee Satisfaction: What You Can Do to Increase Employee Satisfaction. Retrieved from https://www.thebalance.com/keys-to-employee-satisfaction-1918009

Hernandez, S. R. (2009). Strategic Human Resources Management in Health Services Organizations (3rd ed.). Cengage Learning Inc.

Jackson, S., Schuler, R., \& Werner, S. (2011). Managing Human Resources. Mason: Cengage Learning (11th ed.). Cengage Learning.

Johennesse, L.-A. C., \& Chou, T.-K. (2017). Employee Perceptions of Talent Management Effectiveness on Retention. Global Business and Management Research, 9(3), 46-58.

Klein, H. J., Polin, B., \& Sutton, K. L. (2015). Specific Onboarding Practices for the Socialization of New Employees. International Journal of Selection and Assessment, 23(3). https://doi.org/10.1111/ijsa.12113

Klein, H. J., \& Weaver, N. A. (2000). The Effectiveness of An Organizational- Level Orientation Training Program in the Socialization of New Hires. Personnel Psychology, 53. https://doi.org/10.1111/j.1744-6570.2000.tb00193.x

Kossek, E. E., \& Lambert, S. J. (2005). Work and life integration: Organizational, cultural, and individual perspectives. New Jersey: Lawrence Erlbaum Associates Inc.

Langley, A., \& Royer, I. (2006). Perspectives on Doing Case Study Research in Organizations. Management, 9(3), 81-94. https://doi.org/10.3917/mana.093.0081

Lee, T. W., Hom, P., Eberly, M., \& Li, J. (2017). Managing employee retention and turnover with 21st century ideas. 
Organizational Dynamics. https://doi.org/10.1016/j.orgdyn.2017.08.004

Malena, C. (1995). Woking wiyh NGOs. A Practical Guide to Operational Collaboration between The World Bank and Non-governmental Organizations.

Marquardt, M. (2011). Building the Learning Organization: Achieving Strategic Advantage Through a Commitment to Learning (3rd ed.). Boston: Nicholas Brealey Publishing.

Marquis, C., \& Raynard, M. (2015). Institutional Strategies in Emerging Markets. Academy of Management Annals, 9(1), 291-335. https://doi.org/10.1080/19416520.2015.1014661

Marx, M., \& Timmermans, B. (2017). Hiring Molecules, Not Atoms : Comobility and Wages. Organization Science, 28(6), 1115-1133. https://doi.org/10.1287/orsc.2017.1155

McConnell, C. (2011). The Health Care Manager's Legal Guide. New York: Jones and Bartlett Learning,LLC.

McPhie, N. A. G. (2009). Power of Federal Employee Engagement. Washington DC: DIANE Publishing.

MTN Group Limited. (2012). MTN Group Limited Integrated Report for the year ended 31 December 2012. Johannesburg. Retrieved from http://www.mtn-investor.com/mtn_ar2012/pdf/full.pdf

MTN Group Limited. (2014). MTN Group Limited Annual Sustainability Report for the year ended 31 December 2014. Johannesburg. Retrieved from http://www.mtn-investor.com/mtn_ar2014/pdf/sustainability-full.pdf

MTN Press Office. (2014). About Us:Company Profile. Retrieved February 5, 2018, from http://itnewsafrica.com/pressoffices/mtn/aboutus.html

Muratbekova-Touron, M., Kabalina, V., \& Festing, M. (2017). The phenomenon of young talent management in Russia-A context-embedded analysis. Human Resource Management, 1-19.

Nelson, B., \& Spitzer, D. (2003). The 1001 rewards \& recognition field book: the complete guide. New York: Workman Pub.

Ntabgoba, J. (2013). MTN Uganda Recognises Employees Performance and Excellence. Retrieved February 8, 2018, from https://www.mtn.co.ug/new-world/Documents/2013/Feb/MTN Uganda recognises Employees Performance and Excellence.pdf

Phillips, J. J. (2000). Performance analysis and consulting. American Society for Training and Development.

Phillips, J. J., \& Edwards, L. (2008). Managing talent retention: an ROI approach. San Francisco: John Wiley \& Sons.

Pinnington, A., Macklin, R., \& Campbell, T. (2007). Human resource management: ethics and employment. Oxford: Oxford University Press.

Reitman, A. (2007). Talent Retention. American Society for Training and Development.

Scullion, H., \& Collings, D. G. (2010). Global Talent Management. Oxon: Taylor \& Francis.

Sheridan, J. E. (1992). Organizational Culture and Employee Retention. Academy of Management Journal, 35(5), 1036-1056. https://doi.org/10.2307/256539

Silzer, R., \& Dowel, B. E. (2009). Strategy Driven Talent Management: A Leadership Imperative. San Francisco: John Wiley \& Sons.

Stadius, R. (1999). More evaluation instruments. American Society for Training and Development.

Stefan, B., Julian, L., Kathryn, S., Fredrik, A., \& Wachter, T. (2008). The Analysis of Firms and Employees: Quantitative and Qualitative Approaches. Chicago: University of Chicago Press.

Taylor, S. (2002). The employee retention handbook. London: Chartered Institute of Personnel and Development.

Tan, D., \& Rider, C. I. (2017). Let them go? How losing employees to competitors can enhance firm status. Strategic Management Journal, 38(9), 1848-1874. https://doi.org/10.1002/smj.2630

Tan, Y., \& Shen, X. (2016). Socialization Content and Adjustment Outcome: A Longitudinal Study of Chinese Employees Beginning their Career. Social Behavior and Personality, 44(1), 161-176. https://doi.org/10.2224/sbp.2016.44.1.161

Tang, C., Liu, Y., Oh, H., \& Weitz, B. (2014). Socialization Tactics of New Retail Employees: A Pathway to Organizational Commitment. Journal of Retailing, 90(1), 62-73. https://doi.org/10.1016/j.jretai.2013.11.002 
Taylor, S., \& Land, C. (2014). Organizational anonymity and the negotiation of research access. Qualitative Research in Organizations and Management: An International Journal, 9(2), 98-109. https://doi.org/10.1108/QROM-10-2012-1104

Tsui, A. P. Y., \& Lai, K. T. (2009). Professional practices of human resource management in Hong Kong: Linking HRM to organizational success. Hongkong: Hong Kong University Press.

Vallabhaneni, D. (2009). What's Your MBA IQ?: A Manager's Career Development Tool. New Jersey: John Wiley \& Sons.

Wadhwa, A., Bodas Freitas, I. M., \& Sarkar, M. B. (2017). The Paradox of Openness and Value Protection Strategies: Effect of Extramural R\&D on Innovative Performance. Organization Science, 28(5), 873-893. https://doi.org/10.1287/orsc.2017.1145

Wiblen, S. (2016). Framing the usefulness of eHRM in talent management: A case study of talent identification in a professional services firm. Canadian Journal of Administrative Sciences, 33(2), 95-107. https://doi.org/10.1002/cjas.1378

WorldatWork. (2007). The WorldatWork handbook of compensation, benefits \& total rewards: A comprehensive guide for HR professionals. San Francisco: John Wiley \& Sons Inc.

Yu, Y., Yu, Z., \& Zhao, J. (2011). Computer Science for Environmental Engineering and EcoInformatics. New York: Springer.

Zhang, C., \& Stewart, J. (2017). Talent Management and Retention. In Goldstein, H. W., Pulakos, E. D., Passmore, J., \& Semedo, C. (Eds.), The Wiley Blackwell Handbook of the Psychology of Recruitment, Selection and Employee Retention (pp. 473-493). John Wiley \& Sons Ltd. https://doi.org/10.1002/9781118972472.ch22 